\title{
Application of the Theory of Mind, Theory of Executive Functions and Weak Central Coherence Theory to Individuals with ASD
}

\author{
Christine K. Syriopoulou Delli ${ }^{1}$, Asimis Varveris ${ }^{1} \&$ Alexandra Geronta ${ }^{1}$ \\ ${ }^{1}$ Department of Educational and Social Policy, University of Macedonia, Thessaloniki, Greece \\ Correspondence: Christine K. Syriopoulou Delli, Department of Educational and Social Policy, University of \\ Macedonia, Thessaloniki, 156 Egnatia str., 54006, Greece. Tel: 30-693-870-4339. E-mail: csyriop@gmail.com
}

Received: November 21, 2016

Accepted: December 19, 2016 Online Published: December 25, 2016

doi:10.5539/jedp.v7n1p102

URL: http://dx.doi.org/10.5539/jedp.v7n1p102

\begin{abstract}
The present study examined the application of three cognitive theories - the Theory of Mind (ToM) deficit, the Theory of Executive Functions (EF) and Weak Central Coherence Theory (WCC) - in children with Autism Spectrum Disorders (ASD). 9 children with ASD and 18 children of Typical Development (TD) participated in the study. According to the results, most of the children with ASD showed significant deficits in the development of ToM, while a few of them succeeded in all the ToM tests. With regard to EF theory, the children with ASD did not present a deficit in any of the four executive functions in which they were examined, since their performances were similar to those of TD children. As for the WCC theory, the results cannot support the existence of a deficit. However, it seems that children with ASD struggle in respect of global precedence when a local interference effect is present.
\end{abstract}

Keywords: Autism Spectrum Disorders, Theory of Mind, Theory of Executive Functions, Weak Central Coherence Theory

\section{Introduction}

Individuals with Autism Spectrum Disorder (ASD) are characterized by deficits in social communication and social interaction across contexts and restricted, repetitive patterns of behavior, interests or activities (A.P.A., 2013). Cognitive theories investigating the mechanisms that underlie these deficits include the Theory of Mind (ToM), the Executive Functions (EF) theory and the Weak Central Coherence Theory (WCC).

\subsection{Theory of Mind}

Theory of Mind (ToM) is the ability of the individual to attribute such mental states as beliefs, intentions, desires and pretense to themselves and to others and the ability to appreciate that others may have different beliefs, intentions and desires from their own (Mitchell, 1996; Karpinski \& Scullin, 2009). The development of ToM is of paramount importance as people are constantly trying to deduce the emotional and mental states of other people, and it helps in self-organization and self-regulation, as well as in the behavior management of others. On the other hand, restricted development impedes understanding of the social world and employment of the appropriate behavior or strategy in social settings (Doherty, 2008; Korkmaz, 2011). It has been claimed that this inability to "mentalise" is responsible for the failure of individuals with ASD to engage in normal social interaction (Rajendran \& Mitchell, 2007).

Researchers using first- and second-order false belief tests previously argued that children with ASD show significant deficits in ToM development compared to TD children and children with Intellectual Disabilities (ID) (Baron-Cohen, Leslie, \& Frith, 1985; Baron-Cohen, 1989b) and children with Specific Language Impairment (SLI) (Leslie \& Frith, 1988; Perner, Frith, Leslie, \& Leekam, 1989).

Since then, various tests have been devised controlling ToM ability (Wimmer \& Perner, 1983; Perner \& Wimmer, 1985; Baron-Cohen, 1989a; Perner et al., 1989; Zaitchik, 1990; Happe, 1994; Baron-Cohen, Wheelwright, Jolliffe, \& Therese, 1997a; Baron-Cohen, O'Riordan, Stone, Jones, \& Plaisted, 1999; Baron-Cohen, 2000; Gallagher et al., 2000) and studies conducted with ASD individuals have argued that the latter are devoid of a ToM. However, in all the studies there has always been a low percentage of participants with ASD who succeeded in the tests. 
Bowler (1992) claimed that a ToM deficit or delayed ToM development does not characterise all individuals with ASD. Furthermore, Ozonoff, Rogers, and Pennington (1991b) showed that some people with ASD perform as well as TD comparisons in these tests. Apart from that, failure in ToM tests could not totally explain all the features of the disorder.

\subsection{Executive Functions}

Executive Functions Theory emerged partially from the observation that some of the clinical symptoms of autism were similar to those associated with specific brain injury. Features such as the insistence on sameness, difficulty switching attention and a lack of impulse control led researchers to conclude that autism might be explained as a deficit in executive functions (Rajendran \& Mitchell, 2007).

"Executive functions" is an umbrella term that includes a wide range of cognitive processes and behavioral skills and refers to neuropsychological processes that allow physical, cognitive and emotional self-control (Corbett, Constantine, Hendren, Rocke, \& Ozonoff, 2009). It comprises such functions as planning, reasoning, memory, impulse control, inhibition, cognitive flexibility, initiation and monitoring of action, problem-solving, the ability to sustain attention and the ability to deal with novelty (Elliott, 2003; Hill, 2004; Chan, Shum, Toulopoulou, \& Chen, 2008).

Dysfunction of executive functions has been observed in patients with acquired damage to the prefrontal cortex as well as in a range of neurodevelopmental disorders with congenital deficits in this area (Elliott, 2003; Hill, 2004). However, studies have also identified deficits in various executive functions in individuals with ASD, even though there is no apparent damage in the prefrontal lobes (Bennetto, Pennington, \& Rogers, 1996; Corbett et al., 2009). These deficits may explain some clinical behavioral signs of autism, such as rigid behavior, insistence on sameness and inappropriate response to social situations. The present study will deal with the following four executive functions: planning, cognitive flexibility, inhibition and working memory.

\subsubsection{Planning}

Planning is a complex, dynamic function of the brain, in which a sequence of planned actions are generated and constantly controlled, evaluated and updated. An individual should be aware of the current state and the possible changes in order to design an appropriate action plan and accomplish their aim (Owen, 1997; Hill, 2004).

Various studies have researched planning ability in individuals with ASD deficits (Rumsey \& Hamburger, 1988; Prior \& Hoffmann, 1990), especially those which used the Tower of London and Tower of Hanoi tests as their evaluation tool (Ozonoff et al., 1991a; Ozonoff \& McEvoy, 1994; Hughes, Russell, \& Robbins, 1994; Bennetto et al., 1996; Ozonoff \& Jensen, 1999; Verte, Geurts, Roeyers, Oosterlaan, \& Sergeant, 2006; Robinson, Goddard, Dritschel, Wisley, \& Howlin, 2009; Pellicano, 2010a; Zinke et al., 2010).

On the other hand, a number of studies (Goldberg et al., 2005; Happé, Booth, Charlton, \& Hughes, 2006; Corbett et al., 2009) have not confirmed the existence of a planning deficit in individuals with ASD, on the basis of the results obtained with the Stockings of Cambridge evaluation tool, which constitutes a computerised version of the Tower of London and Tower of Hanoi tests. One exception is the study conducted by Ozonoff et al. (2004). Of two studies that used Mazes of WISC-III (Nydén, Gillberg, Hjelmquist, \& Heiman, 1999; Pellicano, Maybery, Durkin, \& Maley, 2006), neither found a deficit in planning. More specifically, Pellicano et al. (2006) used two different tools in the same sample: the Tower of London and the Mazes of WISC-III. The first tool found a statistically significant difference while the second did not.

In short, research reveals a tendency for individuals with ASD to have a deficit in planning. However, the type of tool used may play a mediating role, as studies using the Tower of London and Tower of Hanoi tests found differences while studies using the Stockings of Cambridge and Mazes of WISC did not find differences.

\subsubsection{Cognitive Flexibility}

Cognitive/mental flexibility is defined as the readiness with which an individual's concept system changes in response to environmental stimuli (Scott, 1962). Poor mental flexibility is illustrated by perseverative, stereotyped behavior and difficulties in the regulation and modulation of motor acts, indicating problems in the ability to shift to a different thought or action according to changes in a situation (Hill, 2004).

The majority of studies examining cognitive flexibility have used the Wisconsin Card Sorting Test (WCST) as their evaluation tool, with conflicting results. On the one hand, a number of studies have found significant deficits in individuals with ASD compared to TD individuals (Rumsey \& Hamburger, 1988; Prior \& Hoffmann,1990; Pascualvaca, Fantie, Papageorgiou, \& Mirsky, 1998; Shu, Tien, \& Chen, 2001; Verte et al., 
2006) and also compared to individuals with ADHD, Tourette Syndrome (TS) and ID (Rumsey \& Hamburger, 1990; Ozonoff et al., 1991; Ozonoff \& McEvoy,1994; Bennetto et al., 1996; Ozonoff \& Jensen, 1999).

On the other hand, there have been studies (Minshew, Muenz, Goldstein, \& Payton, 1992; Kaland, Smith, \& Mortensen, 2008; Robinson, Goddard, Dritschel, Wisley, \& Howlin, 2009; Van Eylen et al., 2011) that did not detect any significant difference. Furthermore, Nydén et al. (1999) found that only individuals with ADHD had a statistically significant lower performance in comparison to a TD population. Generally, the WCST has been criticized as it involves several executive functions simultaneously (Ozonoff, Strayer, McMahon, \& Filloux, 1994) and causes difficulties in the interpretation of the results (Hill, 2004).

Instead of WCST, the Intradimensional/Extradimensional Shift task has also been administered, with conflicting results as well. Some studies have detected a deficit in cognitive flexibility (Hughes et al., 1994; Ozonoff et al., 2004; Yerys et al., 2009), while others have detected no deficits at all (Edgin \& Pennington, 2005; Goldberg et al., 2005; Corbett et al., 2009).

Two more tools have been used in the form of the DCCS and Set-Shifting tasks, confirming previous results, in which children with ASD performed significantly worse than TD children (Pellicano et al., 2006; Dichter et al., 2010; Pellicano, 2010a).

It seems that not all individuals within the spectrum are characterised by a deficit in cognitive flexibility, as there are different findings, despite the use of the same tool.

\subsubsection{Inhibition}

Inhibition is the restraint of a mental process, behavior, desire, impulse, in whole or in part, with or without intention (MacLeod, 2007). Studies using a variety of tools have examined the executive function of inhibition with conflicting results, even in studies conducted by the same group of authors. Interpreting results becomes even more difficult due to the great heterogeneity of the control groups. On the one hand, there are findings which support an inhibition deficit in individuals with ASD (Russell, Mauthner, Sharpe, \& Tidswell, 1991; Hughes \& Russell, 1993; Ozonoff et al., 1994; Nydén et al., 1999; Russell et al., 2003; Pellicano et al., 2006; Verte et al., 2006; Corbett et al., 2009; Robinson et al., 2009) while on the other, there are studies that reject the hypothesis of a deficit (Eskes, Bryson, \& McCormick, 1990; Ozonoff \& Strayer, 1997; Ozonoff \& Jensen, 1999; Russell, Jarrold, \& Hood, 1999; Goldberg et al., 2005; Happé et al., 2006).

\subsubsection{Memory}

Memory constitutes the structures and processes involved in the three stages of memory: Encoding, storage and subsequent retrieval of information (McLeod, 2007).

Storage is divided into two subcategories, Short-Term Memory (STM) and Long-Term Memory (LTM) (McLeod, 2007). Baddeley and Hitch (1974) and Baddeley (2002) replaced the concept of STM with the model of Working Memory (WM), which includes STM and a memory which is actively processing information. LTM is divided into declarative and non-declarative memory (Squire \& Dede, 2015). The aim of the present study is to explore whether STM/WM affects individuals with ASD in their daily tasks.

Research findings are even more difficult to explain, due to the plethora of tools used, the complex testing processes and the sensory organ (vision-hearing) being utilized. Studies have used different tools in the same sample of participants with conflicting results. Studies have also been divided into three categories based on their findings: studies that found a deficit in STM/WM in children with ASD (Nydén et al., 1999; Minshew \& Goldstein, 2001; Goldberg et al., 2005; Verte et al., 2006; Steele, Minshew, Luna, \& Sweeney, 2007; Corbett et al., 2009); studies that failed to detect any deficit (Rumsey \& Hamburger, 1988; Ozonoff \& Strayer, 2001; Edgin \& Pennington, 2005; Happé et al., 2006; Chan et al., 2009), and those studies with mixed results (Prior \& Hoffmann, 1990; Rumsey \& Hamburger, 1990; Bennetto et al., 1996; Minshew et al., 1992; Williams, Goldstein, Carpenter, \& Minshew, 2005; Alloway, Rajendran, \& Archibald, 2009; Zinke et al., 2010) owing to an uneven performance across the trials. This has led some researchers to support the view that individuals with ASD present no deficits in memory and merely fail to use the appropriate storage strategies (Minshew et al., 1992; Bennetto et al., 1996). 


\subsection{Weak Central Coherence}

Central coherence is one's ability to process incoming information in its context for higher-level meaning, at the expense of memory for detail (Happé, 1999). Weak Central Coherence theory claims that individuals with ASD tend to process information in a detail-focused way, at the expense of global meaning (Frith, 1989; Frith \& Happé, 1994).

Initially, WCC theory was supported by studies claiming that individuals with ASD either performed significantly better than TD individuals in local precedence tests (Shah \& Frith, 1983, 1993; Jolliffe \& Baron-Cohen, 1997; Plaisted, Swettenham, \& Rees, 1998; O'Riordan, Plaisted, Driver, \& Baron-Cohen, 2001; Pellicano et al., 2006) or showed poor performance in global precedence tests (Rinehart, Bradshaw, Moss, Brereton, \& Tonge, 2000). On the other hand, a number of studies did not confirm the WCC theory (Ozonoff et al., 1994; Brian \& Bryson, 1996).

Happé (1996) claimed that individuals with ASD do not succumb to visual illusions, although these findings were not confirmed by Ropar and Mitchell $(1999,2001)$. Furthermore, Happé (1996) showed that individuals with ASD perform significantly better in local precedence tests only in comparison to younger TD individuals.

Mottron and Belleville (1993) showed that individuals with autism process both at the local and global levels, like the individuals in the TD controls, but there is an interference of the local over the global level when the stimuli are incongruent. Subsequent studies confirmed these findings (Plaisted et al., 1999; Jolliffe \& Baron-Cohen, 2001; Rinehart et al., 2001). More studies were conducted using more than one tool, with mixed findings (Edgin \& Pennington, 2005; Pellicano, 2010a).

The original WCC theory has not been confirmed and the modern trend is for autism to be considered as a multiple deficit (Pellicano et al., 2006; Rajendran \& Mitchell, 2007), combining the three aforementioned theories. However, there has been criticism of the validity of these three theories and the universality of each separately across the spectrum.

\section{The Present Study}

This study aims to investigate whether children with ASD present deficits in the three aforementioned cognitive theories compared to TD children, matched on chronological age and gender. The next aim was to determine possible links between the measures used for the three theories and the independent variables of chronological age, verbal and nonverbal ability and correlations among the measures used for the three theories. The final objective was to investigate the effect of ASD on the performance of each test separately.

\subsection{Method}

\subsubsection{Participants}

A total of 27 children participated in the study: 9 children with ASD ( 8 boys) and 18 TD children (16 boys) matched on chronological age and gender. The ASD group had a mean age of 140.44 months $(\mathrm{SD}=30.10$, range $=100-185)$ and the TD group had a mean age of 141.44 months $(\mathrm{SD}=29.96$, range $=105-187)$. All ASD children had received an independent clinical diagnosis of either autism $(\mathrm{N}=5)$ or Asperger Syndrome $(\mathrm{N}=4)$, according to DSM-IV criteria (APA, 2000). Children diagnosed with a Childhood Disintegrative Disorder or the Pervasive Developmental Disorder NOS were excluded owing to the controversy over DSM-5. All of the children obtained a verbal and nonverbal ability raw score over 11, as assessed by the Vocabulary and Block Design test of the Greek edition of WISC III (Georgas, Paraskevopoulos, Bezevegis, \& Giannitsas, 1997) to prevent failure in tests due to low verbal and nonverbal ability. The participants were recruited following a search in the researcher's broader family and social circles. Each participant with ASD was matched with two TD children of the same gender and chronological age. 6 children with ASD were primary school pupils and 3 secondary school pupils. $12 \mathrm{TD}$ children were primary school pupils and 6 secondary school pupils, respectively.

\subsubsection{Measures}

\section{1) Verbal and nonverbal ability measures}

Vocabulary and Block Design subtests of WISC III (Greek edition) were administered as indices of verbal and nonverbal ability. These two tests have been used together reliably as a short form of WISC-III (Edgin \& Pennington, 2005; van Nieuwenhuijzen \& Vriens, 2012) due to a high correlation with Full Scale IQ (Silverstein, 1970). 
a) Vocabulary: This task is a subtest of WISC III (Greek edition). It consists of a series of orally presented words, which the child orally defines. It is used as an index of verbal ability and carries a maximun score of 60 .

b) Block Design: This task is a subtest of WISC III (Greek edition). It consists of a set of two-dimensional geometric patterns which the child replicates using two colour cubes. It is used as an index of nonverbal ability as it has been standardized to measure intelligence while eliminating the factor of language and carries a maximun score of 69 .

\section{2) Theory of Mind measures}

The children watched eight false-belief tasks-scenarios on a laptop, each of 30-120 duration. The scenarios consisted of three first-order false-belief tasks-scenarios, three second-order false-belief tasks-scenarios and two modified Faux Pas test scenarios (Baron-Cohen et al., 1999). Plastic and paper figures and objects, as well as a Sony Cyber-shot camera were used for the filming of the scenarios. The scripts and the sources of the scenarios are described in detail in Appendix A.

In the first- and second-order false belief tasks, at the end of each trial, the children were asked a critical belief question, a control question and a memory question. A score of 1 was given for each correct answer to a false-belief test question.

a) In the Faux Pas scenarios, the children were asked four questions: a Faux Pas detection question, an identification question, a control question and a False Belief question. The children were given a score of 1 when they answered all four questions correctly. If the children answered the first question incorrectly then the other questions were not asked. There were no memory questions in these two kinds of scenarios.

The maximum score for the false belief tasks and control questions was 8 , while it was 6 for the memory questions. A scenario for familiarization was administered before the false belief tasks, in which two control questions were asked.

\section{3) EF measures}

a) Luria's Handgame (Hughes, 1996). The children were asked to point their index finger and then form a fist, ensuring they could imitate the experimenter. In the Imitation condition, children were told they had to put their hands behind their backs and when the experimenter showed his hand they had to make the same shape (fist or index finger). Out of a total of 10 trials, one point was given, for each correctly imitated trial. In the Conflict condition, children were asked to perform the opposite action. One point was awarded for each successful conflict trial, out of a total of 10 trials. In each condition, the five finger and five fist trials were presented in a randomised order, while the order of presentation of conditions was counterbalanced across participants. High scores on the Conflict condition reflect good inhibitory processes.

b) Digit Span. This task is a subtest of WISC III (Greek edition). It consists of a series of orally presented sequences of digits. The respondent has to repeat these sequences verbatim for Digits Forward, measuring STM and in reverse for Digits Backward, measuring WM. The maximum score for STM is 16, while that for WM is 14 and the composite maximum score is 30 .

c) Card Sorting Task. The children were presented with three teddy bears and three different decks of cards, in terms either of the picture shown (hearts vs. triangles, squares vs. circles, or stars vs. happy faces), color (green vs. pink, blue vs. red, or yellow vs. purple), or picture's size (small vs. large). The children had to work out which cards teddy liked best. When a card was one of teddy's favorites, children turned the card face down in front of the teddy. Alternatively, when a card was not one of teddy's favorites, children turned the card face down far away from the teddy. Feedback was provided after each trial. When six cards in a row were sorted out successfully, or when a maximum of 20 trials had been presented, the sorting rule (e.g., color, shape, size) changed, upon which they were presented with a new teddy bear and a new deck of cards. The children were not alerted to a change in the sorting rule as it was implied in the fact that they were presented with a new situation. Set-shifting performance was rated by the proportion of errors committed following the first sort to criterion (Pellicano, 2010b).

d) Mazes. This task is a subtest of WISC III (Greek edition). Children are required to complete a set of progressively more complex mazes, planning their route ahead, to reach the opening of the maze while making minimal errors. High scores indicate good planning ability. The maximum score is 28 . 


\section{4) Central Coherence measures}

Picture Completion. This task is a subtest of WISC III (Greek edition). It consists of a set of 30 colorful pictures of common objects and scenes, from each of which an important part is missing, which the child has to identify. The task was used in this study to measure local precedence. The maximum score is 30 .

a) Object assembly. This task consists of a set of 5 puzzles of common objects, each presented in a standardized configuration, which the child assembles to form a meaningful whole. It is used to measure the concrete construction of parts to make a recognizable whole. The maximum score is 44 .

\section{General Procedure}

The measures were administered by the principal investigator and a certified psychologist in a quiet room in each of the participants' homes. Initially, researchers informed parents about the nature of the study and, once parental consent had been granted, all the measures were administered within the space of 90 minutes. The measures of verbal and nonverbal ability were always administered first. The order of presentation of the remaining tasks was randomized across participants. A Hewlett Packard 2140 portable computer was also used for observing the ToM tasks.

\section{Results}

\subsection{Preliminary Analyses}

Table 1 presents the descriptive statistics for chronological age, verbal and nonverbal ability. No group differences were found relating to chronological age. As regards nonverbal ability, the TD children performed better than the children with ASD, but the difference was not statistically significant, as the non-parametric Mann-Whitney $\mathrm{U}(\mathrm{z}=1.338, \mathrm{p}=.181)$ indicates.

However, a number of statistically significant differences were found, as the children with ASD performed worse in the vocabulary tests than the TD children, as the non-parametric Mann-Whitney $\mathrm{U}(\mathrm{z}=-2.188, \mathrm{p}=.029)$ shows. This finding is consistent with the fact that children with ASD are likely to fall behind in language development in comparison to TD children of the same age (Tager-Flusberg, 1999; A.P.A., 2013).

Table 1. Descriptive statistics for chronological age, verbal and nonverbal ability

\begin{tabular}{lll}
\hline & & Group \\
\hline Variables & ASD & TD \\
\hline Age (months) & $(\mathrm{N}=9)$ & $(\mathrm{N}=18)$ \\
Mean & 140.44 & 141.44 \\
SD & 30.10 & 29.96 \\
Range & $100-185$ & $105-187$ \\
Vocabulary (out of 60) & & 32.17 \\
Mean & $23.44 *$ & 7.641 \\
SD & 9.369 & $20-47$ \\
Range & $11-36$ & \\
Block Design (out of 69) & & 44.67 \\
Mean & 37.56 & 11.01 \\
SD & 13.333 & $26-63$ \\
Range & $20-60$ & \\
\hline *5 (two tailed) & & \\
& & \\
\hline
\end{tabular}




\subsection{Theory of Mind Results}

Table 2 presents the mean performance of the two groups on the ToM tasks. The children with ASD performed worse at all levels of ToM compared to the TD children. This difference is statistically significant in the ToM first-order false belief tests as the Mann-Whitney $\mathrm{U}(\mathrm{z}=-3.426, \mathrm{p}=.001)$ shows, at a significance level of $\mathrm{a}=$ 0.05 , and in the ToM composite score $(\mathrm{z}=-2.198, \mathrm{p}=.028)$. This poor performance in the ToM tests does not stem from memory problems or misunderstanding of stories, as the children with ASD had high scores both in the control and memory questions.

Table 2. Mean performance on Theory of Mind tasks

\begin{tabular}{|c|c|c|}
\hline \multirow{3}{*}{ Measure } & \multicolumn{2}{|c|}{ Group } \\
\hline & ASD & $\mathrm{TD}$ \\
\hline & $(\mathrm{N}=9)$ & $(\mathrm{N}=18)$ \\
\hline \multicolumn{3}{|c|}{ ToM $1^{\text {st }}$ Order (out of 3) } \\
\hline Mean & $2.33 *$ & 3.00 \\
\hline SD & .707 & .00 \\
\hline Range & $1-3$ & 3 \\
\hline \multicolumn{3}{|c|}{ ToM $2^{\text {st }}$ Order (out of 3) } \\
\hline Mean & 1.44 & 2.50 \\
\hline SD & 1.509 & .514 \\
\hline Range & $0-3$ & $2-3$ \\
\hline \multicolumn{3}{|c|}{ ToM Faux Pas (out of 2) } \\
\hline Mean & 1.44 & 1.83 \\
\hline SD & .726 & .383 \\
\hline Range & $0-2$ & $1-2$ \\
\hline \multicolumn{3}{|c|}{ ToM Composite (out of 8) } \\
\hline Mean & $5.22 *$ & 7.33 \\
\hline SD & 2.33 & .594 \\
\hline Range & $2-8$ & $6-8$ \\
\hline \multicolumn{3}{|c|}{ Control questions } \\
\hline Mean & 7.44 & 7.94 \\
\hline SD & .726 & .236 \\
\hline Range & $6-8$ & $7-8$ \\
\hline \multicolumn{3}{|c|}{ Memory questions } \\
\hline Mean & 5.78 & 6 \\
\hline SD & .441 & .000 \\
\hline Range & $5-6$ & 6 \\
\hline
\end{tabular}

$* \mathrm{p}<.05$ (two tailed)

Table 3 presents the frequencies of correct responses for the two groups in the ToM false belief tests. In the first-order false belief tasks, all the TD children passed all 3 scenarios successfully, while only 4 children with ASD passed all 3, revealing a decline in ToM development. In the second-order false belief tasks, due to the greater degree of difficulty, 4 children with ASD failed to give any correct response, while half of the TD group answered all three false belief tasks correctly and the other half answered at least 2 false belief tasks correctly. In 
the Faux Pas false belief tasks the children with ASD performed better in comparison to their performance in the previous tasks. It seems that these kinds of ToM tasks are easier for them to understand.

Table 3. Frequencies of correct responses in ToM false belief tests

\begin{tabular}{|c|c|c|c|c|c|c|}
\hline & \multicolumn{6}{|c|}{ Group } \\
\hline & \multirow{2}{*}{\multicolumn{2}{|c|}{$\begin{array}{l}\text { ASD } \\
(\mathrm{N}=9)\end{array}$}} & & \multirow{2}{*}{\multicolumn{2}{|c|}{$\begin{array}{l}\mathrm{TD} \\
(\mathrm{N}=18)\end{array}$}} & \\
\hline & & & & & & \\
\hline Correct responses & ToM $1^{\text {st }}$ order & ToM $2^{\text {nd }}$ order & ToM Faux Pas & ToM $1^{\text {st }}$ order & ToM $2^{\text {nd }}$ order & ToM Faux Pas \\
\hline $\mathbf{0}$ & - & 4 & 1 & - & - & - \\
\hline 1 & 1 & 1 & 3 & - & - & 3 \\
\hline 2 & 4 & - & 5 & - & 9 & 15 \\
\hline 3 & 4 & 4 & N/A & 18 & 9 & N/A \\
\hline
\end{tabular}

N/A: Not available

\subsection{Executive Function Results}

Table 4 presents the mean performance of the two groups on the four Executive Function tasks. Both groups had a similar performance on the inhibition and planning measures. On the memory and cognitive flexibility measures, the children with ASD performed slightly worse than their TD comparisons, without the result being statistically significant. Therefore, the hypothesis of a deficit in these executive functions cannot be supported, according to the results of this study.

Table 4. Mean performance on Executive Function tasks

\begin{tabular}{|c|c|c|}
\hline \multirow{3}{*}{ Measure } & \multicolumn{2}{|c|}{ Group } \\
\hline & ASD & $\mathrm{TD}$ \\
\hline & $(\mathrm{N}=9)$ & $(\mathrm{N}=18)$ \\
\hline \multicolumn{3}{|c|}{ Luria's Handgame (out of 10) } \\
\hline Mean & 8.78 & 8.78 \\
\hline SD & 1.48 & 1.39 \\
\hline Range & $6-10$ & $5-10$ \\
\hline \multicolumn{3}{|c|}{ Mazes (out of 28) } \\
\hline Mean & 19.44 & 19.1 \\
\hline SD & 5.50 & 4.28 \\
\hline Range & $12-26$ & $13-27$ \\
\hline \multicolumn{3}{|c|}{ Memory forward (out of 16) } \\
\hline Mean & 7.00 & 8.44 \\
\hline SD & 2.50 & 1.68 \\
\hline Range & $4-12$ & $5-11$ \\
\hline \multicolumn{3}{|c|}{ Memory backwards (out of 14) } \\
\hline Mean & 5.44 & 5.78 \\
\hline SD & 3.71 & 2.01 \\
\hline Range & $2-14$ & $3-11$ \\
\hline
\end{tabular}




\begin{tabular}{lll}
\hline Memory composite (out of 30) & & 14.22 \\
Mean & 12.44 & 3.30 \\
SD & 6.02 & $10-22$ \\
Range & $8-26$ & \\
Card Sorting Task (out of 60)** & & 27.06 \\
Mean & 28.78 & 5.87 \\
SD & 4.41 & $21-44$ \\
Range & $24-37$ & \\
\hline
\end{tabular}

$* \mathrm{p}<.05$ (two tailed)

**60 is the worst possible score and 18 the best

\subsection{Weak Central Coherence Results}

Table 5 presents the mean performance of the two groups on two Central Coherence tasks. In the picture completion, in which local precedence is investigated, both groups performed similarly. In the object assembly, in which global precedence is investigated, the TD children achieved a better score than the children with ASD, although the difference in scores was not statistically significant. The results do not permit us to support the WCC theory, although the difficulty of children with ASD in a global precedence task, where a transition from partial to holistic is required, is reflected.

Table 5. Mean performance on Central Coherence tasks

\begin{tabular}{lll}
\hline & & Group \\
\hline Measure & ASD & TD \\
& $(\mathrm{N}=9)$ & $(\mathrm{N}=18)$ \\
\hline Picture completion (out of 30) & & \\
Mean & 18.78 & 19.83 \\
SD & 3.42 & 3.46 \\
Range & $13-24$ & $14-24$ \\
Object assembly (out of 44) & & \\
Mean & 21.56 & 25.17 \\
SD & 6.91 & 6.75 \\
Range & $8-30$ & $13-34$ \\
\hline
\end{tabular}

$* \mathrm{p}<.05$ (two tailed)

\section{The Relationships between Cognitive Measures in All Three Domains with Age, Verbal and Nonverbal Sbility for the ASD and TD Groups}

For both groups, the analyses revealed significant relationships (Table 6). For the ASD group, age was highly correlated with ToM $(r=.865, \mathrm{p}<.01)$, planning $(\mathrm{r}=.916, \mathrm{p}<.01)$ and local precedence task $(\mathrm{r}=.727, \mathrm{p}<.05)$. Verbal ability was highly correlated with ToM $(\mathrm{r}=.795, \mathrm{p}<.05)$, planning $(\mathrm{r}=.854, \mathrm{p}<.01)$ and local precedence task $(\mathrm{r}=.725, \mathrm{p}<.05)$ and nonverbal ability was highly correlated with ToM $(\mathrm{r}=.896, \mathrm{p}<.01)$, planning $(\mathrm{r}=.756, \mathrm{p}<.05)$ and local precedence task $(\mathrm{r}=.724, \mathrm{p}<.05)$. The lack of correlations with other tasks possibly reflects the great heterogeneity that exists amongst the skills of children with ASD.

On the other hand, for the TD group, no correlation was found between these three indicators and ToM. This finding seemed reasonable as we expected all the TD children over the age of 6 years to pass the majority of the ToM tests. As regards the EF and CC measures, correlations were revealed with at least two of the three indicators. 
Table 6. Pearson correlations between cognitive measures in all three domains with age, verbal and nonverbal ability for ASD and TD groups

\begin{tabular}{|c|c|c|c|c|}
\hline Group & Measure & Age & Verbal ability & Nonverbal ability \\
\hline \multirow[t]{9}{*}{ ASD } & ToM & $.865^{* *}$ & $.795 *$ & $.896 * *$ \\
\hline & Mazes & $.916^{* *}$ & $.854 * *$ & $.756^{*}$ \\
\hline & Luria's Handgame & -.112 & -.298 & -.063 \\
\hline & Memory forward & .336 & .368 & .041 \\
\hline & Memory backwards & .609 & .576 & .280 \\
\hline & Memory composite & .515 & .508 & .190 \\
\hline & Card Sorting Task & .098 & .121 & -.083 \\
\hline & Picture completion & $.727 *$ & $.725^{*}$ & $.724 *$ \\
\hline & Object assembly & .538 & .299 & .613 \\
\hline \multirow[t]{9}{*}{ TD } & ToM & -.115 & -.350 & -.171 \\
\hline & Mazes & $.652 * *$ & .438 & $.538^{*}$ \\
\hline & Luria's Handgame & $.514^{*}$ & $.693 * *$ & .255 \\
\hline & Memory forward & .426 & $.591 * *$ & $.562 *$ \\
\hline & Memory backwards & $.479 *$ & $.575^{*}$ & .425 \\
\hline & Memory composite & $.510^{*}$ & $.654 * *$ & $.547^{*}$ \\
\hline & Card Sorting Task & $-.579 *$ & $-.566^{*}$ & -.260 \\
\hline & Picture completion & $.603 * *$ & $.680 * *$ & $.548^{*}$ \\
\hline & Object assembly & .340 & $.521 *$ & $.754 * *$ \\
\hline
\end{tabular}

$* \mathrm{p}<.05$ (two tailed)

$* * \mathrm{p}<.01$ (two tailed)

\subsection{The Relationships of Cognitive Tasks across Groups}

As shown in Table 7, for the ASD group, a strong, positive correlation was found between ToM and picture completion $(\mathrm{r}=.728, \mathrm{p}<.05)$, between mazes and memory backwards $(\mathrm{r}=.668, \mathrm{p}<.05)$ and between memory composite and the card sorting task $(\mathrm{r}=.682, \mathrm{p}<.05)$. For the TD group, a series of correlations were revealed and are set out in detail in Table 8 .

Table 7. Pearson correlations of cognitive tasks for ASD group

\begin{tabular}{lllllllll}
\hline & $\begin{array}{l}\text { Luria's } \\
\text { Handgame }\end{array}$ & Mazes & $\begin{array}{l}\text { Memory } \\
\text { forward }\end{array}$ & $\begin{array}{l}\text { Memory } \\
\text { backwards }\end{array}$ & $\begin{array}{l}\text { Memory } \\
\text { composite }\end{array}$ & $\begin{array}{l}\text { Card } \\
\text { Sorting }\end{array}$ & $\begin{array}{l}\text { Picture } \\
\text { completion }\end{array}$ & $\begin{array}{l}\text { Object } \\
\text { assembly }\end{array}$ \\
\hline ToM & -.201 & .653 & .000 & .362 & .223 & -.128 & $.728^{*}$ & .456 \\
Luria's Handgame & & -.048 & .473 & .361 & .419 & .585 & -.554 & -.133 \\
Mazes & & & .473 & $.668^{*}$ & .608 & .365 & .564 & .535 \\
Memory forward & & & & $.876^{* *}$ & $.955^{* *}$ & .658 & -.190 & -.318 \\
\hline
\end{tabular}




\begin{tabular}{|c|c|c|c|c|}
\hline Memory backwards & $.980 * *$ & .664 & .058 & -.079 \\
\hline Memory composite & & $.682 *$ & -.043 & -.181 \\
\hline Card sorting & & & -.426 & -.008 \\
\hline Picture completion & & & & .545 \\
\hline
\end{tabular}

Table 8. Pearson correlations of cognitive tasks for TD group

\begin{tabular}{|c|c|c|c|c|c|c|c|c|}
\hline & $\begin{array}{l}\text { Luria's } \\
\text { Handgame }\end{array}$ & Mazes & $\begin{array}{l}\text { Memory } \\
\text { forward }\end{array}$ & $\begin{array}{l}\text { Memory } \\
\text { backwards }\end{array}$ & $\begin{array}{l}\text { Memory } \\
\text { composite }\end{array}$ & $\begin{array}{l}\text { Card } \\
\text { Sorting }\end{array}$ & $\begin{array}{l}\text { Picture } \\
\text { completion }\end{array}$ & $\begin{array}{l}\text { Object } \\
\text { assembly }\end{array}$ \\
\hline ToM & -.260 & .170 & -.215 & .065 & -.070 & .095 & -.228 & -.425 \\
\hline Luria's Handgame & & .349 & .419 & .462 & $.497 *$ & $-.565^{*}$ & .344 & .347 \\
\hline Mazes & & & $.497 *$ & .296 & .435 & -.437 & .449 & .355 \\
\hline Memory forward & & & & $.584 *$ & $.868 * *$ & -.234 & $.516^{*}$ & $.612 * *$ \\
\hline Memory backwards & & & & & $.910 * *$ & -.401 & .449 & .258 \\
\hline Memory composite & & & & & & -.365 & $.538^{*}$ & $.470^{*}$ \\
\hline Card Sorting & & & & & & & $-.490 *$ & -.122 \\
\hline Picture completion & & & & & & & & $.491 *$ \\
\hline
\end{tabular}

$* \mathrm{p}<.05$ (two tailed)

$* * \mathrm{p}<.01$ (two tailed)

\subsection{Regression Analysis}

Seven econometric models were analyzed with the regression analysis method. The cognitive measures of the three theories were used as dependent variables, while sex, group, educational level (primary and secondary level) and age were used as independent variables. The results were controlled for the existence of heteroscedasticity, using the White control, for the existence of autocorrelation, using the Breusch-Godfrey control, and for multicollinearity, using VIF (variance inflation index). None of these affected the results of the present study.

Out of seven models, only regression analyses for ToM revealed group effect (Table 9). The constant was a $=0.1$, while the variable «group» was statistically significant at significance level $\mathrm{a}=0.05$. The evidence indicates that children with ASD will present a worse performance in ToM tasks in comparison to TD children of the same age (-2.108). 
Table 9. Regression analyses for ToM

\begin{tabular}{llllll}
\hline Variable & Unstand. Coefficient & Std error & t-statistic & Sig & VIF \\
\hline Constant & 6.925 & 3.985 & 1.738 & $.096^{* *}$ & $N / A$ \\
Sex & .595 & .982 & .606 & .551 & 1.434 \\
Group & $\mathbf{- 2 . 1 0 8}$ & .547 & -3.852 & $\mathbf{. 0 0 1 *}$ & 1.002 \\
Educational level & -.928 & 1.393 & -.666 & .512 & 6.495 \\
Age & .004 & .024 & .144 & .887 & 7.504 \\
R-squared & 0.483 & & & & \\
\hline
\end{tabular}

*95\% confidence interval, **confidence interval $90 \%$

\section{Discussion}

According to the results of this study, a deficit in the development of ToM appears in children with ASD. This has also been supported by a number of other studies (Happé, 1994; Baron-Cohen et al., 1997b; Baron-Cohen et al., 1999; Pellicano et al., 2006; Pellicano, 2010a). However, the results should be treated with caution. Firstly, in spite of the fact that the degree of difficulty remains the same, for instance in the first-order tasks, children with ASD succeeded in scenarios that differed from each other. Thus, if a child fails in a single task, this does not automatically mean that they have not reached a specific developmental stage. This fact should be emphasized because early research used only one scenario to demonstrate if children succeeded or not in the first and second-order tasks of ToM (Baron-Cohen et al., 1985; Baron-Cohen, 1989b; Perner et al., 1989; Bowler, 1992). Secondly, on many occasions no absolute success or absolute failure could be identified in their performance, as children succeeded in different scenarios at all three levels. Furthermore, children with ASD performed much better in the modified Faux Pas tasks, highlighting the fact that there are more nuances in the development of ToM to be explored, since children with ASD seemed to have a better grasp of the false beliefs in more difficult circumstances.

Despite the apparent difficulty of children with ASD in successfully completing the false belief tasks, the universality of the phenomenon cannot be supported as there is a percentage of individuals who succeed in the first and second-order false belief tests (Bowler, 1992). It is possible that a delay in the development of ToM and not necessarily a deficit, affected by delayed language development, may be responsible for underperformance. Happé (1995) found that verbal mental age is the main predictor of success in first-order false belief tests for individuals with ASD, while for TD children, the main predictors are both age and verbal mental age.

Mitchell's suggestion (1996) that children with ASD may not pass false belief tests because they are locked into "current reality", where the object is placed, without taking into consideration another's person belief about where it might be, should also be taken into account. Additionally, the mechanisms used by children with ASD in order to succeed in a ToM false belief task are not certain. Although a child may have passed a ToM test, it may not have developed the ability of empathy, merely solving the task as if it were a mathematical problem (Pellicano et al., 2006; Rajendran \& Mitchell, 2007).

Regarding EF theory, the children with ASD did not present any deficit in the four executive functions investigated. First of all, the children with ASD were not found to have a deficit in inhibition in comparison to the TD children. This finding is consistent with several studies (Eskes et al., 1990; Ozonoff \& Jensen, 1999; Happé et al., 2006), though not with that by Pellicano et al. (2006) who used the same instrument. This discrepancy among studies may have occurred due to the age difference of the participants, as in that study (Pellicano et al., 2006) the participants were 4-7 years old, while in this study the participants were 8-15 years old. We assume that a possible delay in the development of EF in the early years may not be apparent as children with ASD grow.

With regard to the planning function, both groups displayed equal capability. They had almost the same score, therefore it would seem wrong to assume the existence of a deficit. In this finding, the specific assessment tool used might have played a mediative role as no differences were found in other studies that used the same instrument (Nydén et al., 1999; Pellicano et al., 2006).

In the Executive function of memory, the children with ASD had marginally lower scores in relation to the TD children. The findings of this study are consistent with those of other studies that used the same instruments 
(Rumsey \& Hamburger, 1990; Minshew et al., 1992; Bennetto et al., 1996). In fact, a great diversity in the responses amongst participants was revealed. On the one hand, there were children with ASD who surpassed all the TD children, while, on the other, there were also ASD children with very low scores.

As for the cognitive flexibility function, the children with ASD performed slightly worse than the TD children, without this difference being statistically significant. These findings contradict those of other studies using the same instrument (Pellicano et al., 2006; Pellicano, 2010a). The difference may be due to the age difference between the participants. However, this finding is consistent with those of other studies that used different tools (Edgin \& Pennington, 2005; Goldberg et al., 2005; Corbett et al., 2009).

The finding that emerges from all these EF tests is that children with ASD constitute a capable group, in which various individuals surpassed their TD peers in various tests. Therefore, it is evident that children with ASD have also strengths and weaknesses like their TD comparisons. Even studies that found a deficit in EF, claimed that these deficits characterized only half of their sample of children with ASD (Pellicano et al., 2006).

Regarding WCC theory, in the picture completion task the children with ASD achieved slightly lower scores than their TD comparisons. In contrast to research supporting the superiority of children with ASD in local precedence (Shah \& Frith, 1983; Jolliffe \& Baron-Cohen, 1997), according to the results of this study, the children with ASD presented the same performance patterns as those of the TD children, consistent with other studies that did not confirm the superiority of ASD children over TD children of the same age (Brian \& Bryson, 1996; Ropar \& Mitchell, 1999, 2001).

In the object assembly task, the children with ASD obtained lower scores than the TD children, although the difference was not statistically significant. However, this difference might reflect their difficulty in global precedence where local interference takes place, as they needed more time and less successful connections were completed. Although our data and the current trend in research (Rajendran \& Mitchell, 2007) do not permit us to support the WCC theory, children seem to prefer local over global processing and, furthermore, find global processing difficult when it consists of smaller incongruent parts (Mottron \& Belleville, 1993). It seems rather to be a case of a personal information processing style (Happé, 1999), without, however, being a universal feature over the entire spectrum.

In our attempts to find correlations among the tests performed for the three cognitive theories, in the case of the ASD group, a high correlation was found between the ToM tests and the picture completion task. Children demonstrating good local precedence succeeded in the false belief tests. It could be assumed that even a detail-focused processing style can help them understand and attribute beliefs to others. A high correlation was also found between the results of the mazes task and memory backwards. This finding might indicate the strategy that was followed, as many children mentally started from the exit of the maze, proceeded to the center and then solved the maze problem. Conversely, in the TD group a high correlation was found between the results of the mazes task and memory forward, which perhaps suggests a different planning strategy.

Moreover, a high correlation was found between the memory composite score and the results of the card sorting task for the ASD group. This finding seems reasonable since it is necessary to remember features of the first and the following cards in order to identify the sort criterion with the fewest possible cards. A negative correlation was also found between the results of the Luria's handgame and card sorting tasks for the ASD group. Low scores on the inhibition task means that the child exhibits impulsive behavior, while a high score in the card sorting task means a weak performance in cognitive flexibility. So, the more impulsive a child is, the more likely it is to fail to inhibit itself, giving a wrong answer in the cognitive flexibility task.

For the TD group, a high correlation was found between the results of the picture completion task and the object assembly task, suggesting that both local and global precedence are equally developed processing styles, in contrast to children with ASD, where such a correlation is not apparent.

Due to the fact that different correlations were revealed among the tests investigating various abilities, it should be borne in mind that when a test is administered, it is difficult to isolate and investigate a single ability on its own, as in most tasks individuals must employ a range of skills, like memory, inhibition and planning. Therefore, terms like "deficit" or "dysfunction", should be used cautiously every time a child fails in a test, because it is impossible to be absolutely sure about the underlying mechanisms that caused a child to underperform.

As mentioned earlier, individuals with ASD must be considered as a heterogeneous group with varying strengths and weaknesses. Theories can help delineate a general profile and outline the main difficulties faced by this 
group in its daily activities. Beyond that, however, our belief is that children with ASD require individualized educational programs that take advantage of their strengths and improve their weaknesses.

\subsection{Limitations and Suggestions for Future Research}

The conclusions drawn from this research are subject to a number of limitations. The first of these is the low sample number of ASD participants that affects the effect size of the study. We should be careful when interpreting the results, as some tendencies could well be due to this low sample size. The second limitation is the heterogeneity of the ASD participants, as 5 children had received an independent clinical diagnosis of autism and 4 children had received an independent clinical diagnosis of Asperger Syndrome, according to DSM-IV criteria (APA, 2000). However, since new diagnostic criteria released in the DSM V (A.P.A., 2013) these 2 groups fall within the same group. Another limitation is the administration of the vocabulary and Block Design subtests as indicators of verbal and nonverbal ability in order to reduce the length of the experimental procedure. It would have been more appropriate to use the Peabody Picture Vocabulary Test and the Leiter scale for measuring verbal and non-verbal ability, respectively.

Regarding recommendations for future research, more studies should be conducted in which children's performances in relation to the three above mentioned theories should be assessed on an annual basis. This would help us monitor their progress and identify possible links with verbal, non verbal and chronological age, and plan age appropriate interventions. Furthermore, each theory or ability should be investigated by at least two tools and the existing assessment tools should be improved and new tools should be introduced which will be more accurate and will give a clearer picture, in spite of the heterogeneity that exists in the profile of individuals with ASD. Finally, future studies should also include educational interventions to determine which of these improve the abilities of children with ASD and establish differentiated teaching programs that will be based on research data.

\section{References}

Alloway, T. P., Rajendran, G., \& Archibald, L. M. (2009). Working memory in children with developmental disorders. Journal of Learning Disabilities, 42(4), 372-382. https://dx.doi.org/10.1177/0022219409335214

American Psychiatric Association. (2000). DSM-IV-TR; Diagnostic and statistical manual of mental disorders, text revision. Washington, D.C: American Psychiatric Association.

American Psychiatric Association. (2013). The Diagnostic and Statistical Manual of Mental Disorders; DSM 5. Bookpoint US.

Baddeley, A. D. (2002). Is working memory still working? European Psychologist, 7(2), 85. https://dx.doi.org/10.1027//1016-9040.7.2.85

Baddeley, A. D., \& Hitch, G. (1974). Working memory. Psychology of Learning and Motivation, 8, 47-89. https://dx.doi.org/10.1016/S0079-7421(08)60452-1

Baron-Cohen, S. (1989a). Are autistic children "behaviorists"? An examination of their mental, physical and appearance-reality distinctions. J Autism Dev Disord, 19(4), 579-600. https://dx.doi.org/10.1007/BF02212859

Baron-Cohen, S. (2000). Theory of mind and autism; A review. International Review of Research in Mental Retardation, 23, 169-184. https://dx.doi.org/10.1016/S0074-7750(00)80010-5

Baron-Cohen, S., Leslie, A. M., \& Frith, U. (1985). Does the autistic child have a "theory of mind"? Cognition, 21(1), 37-46. https://dx.doi.org/10.1016/0010-0277(85)90022-8

Baron-Cohen, S., O'Riordan, M., Stone, V., Jones, R., \& Plaisted, K. (1999). Recognition of faux pas by normally developing children and children with Asperger syndrome or high-functioning autism. $J$ Autism Dev Disord, 29(5), 407-418. https://dx.doi.org/10.1023/A:1023035012436

Baron-Cohen, S., Wheelwright, S., \& Jolliffe, T. (1997a). Is there a "language of the eyes"? Evidence from normal adults, and adults with autism or Asperger syndrome. Visual Cognition, 4(3), 311-331. https://dx.doi.org/10.1080/713756761

Baron-Cohen, S. (1989b). The autistic child's theory of mind; A case of specific developmental delay. Journal of Child Psychology and Psychiatry, 30(2), 285-297. 
Baron-Cohen, S., Jolliffe, T., Mortimore, C., \& Robertson, M. (1997b). Another advanced test of theory of mind; Evidence from very high functioning adults with autism or Asperger syndrome. Journal of Child Psychology and Psychiatry, 38(7), 813-822. https://dx.doi.org/10.1111/j.1469-7610.1997.tb01599.x

Bennetto, L., Pennington, B. F., \& Rogers, S. J. (1996). Intact and impaired memory functions in autism. Child Development, 67(4), 1816-1835. https://dx.doi.org/10.1111/j.1467-8624.1996.tb01830.x

Bowler, D. M. (1992). "Theory of Mind" in Asperger's Syndrome. Journal of Child Psychology and Psychiatry, 33(5), 877-893. https://dx.doi.org/10.1111/j.1469-7610.1992.tb01962.x

Brian, J. A., \& Bryson, S. E. (1996). Disembedding performance and recognition memory in autism/PDD. $\begin{array}{lllll}\text { Journal of Child Psychology and Psychiatry, 37(7), 865-872. } & \end{array}$ https://dx.doi.org/10.1111/j.1469-7610.1996.tb01482.x

Chan, A. S., Cheung, M. C., Han, Y. M. Y., Sze, S. L., Leung, W. W., Man, H. S., \& To, C. Y. (2009). Executive function deficits and neural discordance in children with Autism Spectrum Disorders. Clinical Neurophysiology, 120(6), 1107-1115. https://dx.doi.org/10.1016/j.clinph.2009.04.002

Chan, R. C., Shum, D., Toulopoulou, T., \& Chen, E. Y. (2008). Assessment of executive functions; Review of instruments and identification of critical issues. Archives of Clinical Neuropsychology, 23(2), 201-216. https://dx.doi.org/10.1016/j.acn.2007.08.010

Corbett, B. A., Constantine, L. J., Hendren, R., Rocke, D., \& Ozonoff, S. (2009). Examining executive functioning in children with autism spectrum disorder, attention deficit hyperactivity disorder and typical development. Psychiatry Research, 166(2), 210-222. https://dx.doi.org/10.1016/j.psychres.2008.02.005

Dichter, G. S., Radonovich, K. J., Turner-Brown, L. M., Lam, K. S., Holtzclaw, T. N., \& Bodfish, J. W. (2010). Performance of children with autism spectrum disorders on the dimension-change card sort task. $J$ Autism Dev Disord, 40(4), 448-456. https://dx.doi.org/10.1007/s10803-009-0886-1

Doherty, M. J. (2008). Theory of mind; How children understand others' thoughts and feelings. New York: Psychology Press.

Edgin, J. O., \& Pennington, B. F. (2005). Spatial cognition in autism spectrum disorders; Superior, impaired, or just intact? J Autism Dev Disord, 35(6), 729-745. https://dx.doi.org/10.1007/s10803-005-0020-y

Elliott, R. (2003). Executive functions and their disorders. Imaging in clinical neuroscience. British Medical Bulletin, 65(1), 49-59. https://dx.doi.org/10.1093/bmb/65.1.49

Eskes, G. A., Bryson, S. E., \& McCormick, T. A. (1990). Comprehension of concrete and abstract words in autistic children. $J$ Autism Dev Disord, 20(1), 61-73. https://dx.doi.org/10.1007/BF02206857

Frith, U. (1989). Autism; Explaining the enigma. USA: Blackwell Plc.

Frith, U., \& Happé, F. (1994). Autism; Beyond "theory of mind". Cognition, 50(1), 115-132. https://dx.doi.org/10.1016/0010-0277(94)90024-8

Gallagher, H. L., Happé, F., Brunswick, N., Fletcher, P. C., Frith, U., \& Frith, C. D. (2000). Reading the mind in cartoons and stories; an fMRI study of "theory of mind" in verbal and nonverbal tasks. Neuropsychologia, 38(1), 11-21. https://dx.doi.org/10.1016/S0028-3932(99)00053-6

Georgas, D. D., Paraskevopoulos, I. N., Bezevegis, I. G., \& Giannitsas, N. D. (1997). Greek WISC-III: Wechsler intelligence scales for children [in Greek]. Athens, Greece: Ellinika Grammata.

Goldberg, M., Mostofsky, S., Cutting, L., Mahone, E., Astor, B., Denckla, M., \& Landa, R. (2005). Subtle executive impairment in children with autism and children with ADHD. J Autism Dev Disord, 35(3), 279-293. https://dx.doi.org/10.1007/s10803-005-3291-4

Happé, F. (1999). Autism; cognitive deficit or cognitive style? Trends in Cognitive Sciences, 3(6), 216-222. https://dx.doi.org/10.1016/S1364-6613(99)01318-2

Happé, F., Booth, R., Charlton, R., \& Hughes, C. (2006). Executive function deficits in autism spectrum disorders and attention-deficit/hyperactivity disorder; examining profiles across domains and ages. Brain and Cognition, 61(1), 25-39. https://dx.doi.org/10.1016/j.bandc.2006.03.004

Happé, F. G. (1994). An advanced test of theory of mind; Understanding of story characters' thoughts and feelings by able autistic, mentally handicapped, and normal children and adults. J Autism Dev Disord, 24(2), 129-154. https://dx.doi.org/10.1007/BF02172093 
Happé, F. G. (1995). The role of age and verbal ability in the theory of mind task performance of subjects with autism. Child Development, 66(3), 843-855. https://dx.doi.org/10.1111/j.1467-8624.1995.tb00909.x

Happé, F. G. (1996). Studying weak central coherence at low levels; children with autism do not succumb to visual illusions. A research note. Journal of Child Psychology and Psychiatry, 37(7), 873-877. https://dx.doi.org/10.1111/j.1469-7610.1996.tb01483.x

Hill, E. L. (2004). Executive dysfunction in autism. Trends in Cognitive Sciences, 8(1), 26-32. https://dx.doi.org/10.1016/j.tics.2003.11.003

Hughes, C., \& Russell, J. (1993). Autistic children's difficulty with mental disengagement from an object; Its implications for theories of autism. Developmental Psychology, 29(3), 498. https://dx.doi.org/10.1037/0012-1649.29.3.498

Hughes, C., Russell, J., \& Robbins, T. W. (1994). Evidence for executive dysfunction in autism. Neuropsychologia, 32(4), 477-492. https://dx.doi.org/10.1016/0028-3932(94)90092-2

Hughes, C. (1996). Control of action and thought: Normal development and dysfunction in autism: A research note. Journal of Child Psychology and Psychiatry, 37(2), 229-236. https://dx.doi.org/10.1111/j.1469-7610.1996.tb01396.x

Jolliffe, T., \& Baron-Cohen, S. (2001). A test of central coherence theory; Can adults with high-functioning autism or Asperger syndrome integrate fragments of an object? Cognitive Neuropsychiatry, 6(3), 193-216. https://dx.doi.org/10.1080/13546800042000124

Jolliffe, T., \& Baron-Cohen, S. (1997). Are people with autism and Asperger syndrome faster than normal on the Embedded Figures Test? Journal of Child Psychology and Psychiatry, 38(5), 527-534. https://dx.doi.org/10.1111/j.1469-7610.1997.tb01539.x

Kaland, N., Smith, L., \& Mortensen, E. L. (2008). Brief report; cognitive flexibility and focused attention in children and adolescents with Asperger syndrome or high functioning autism as measured on the computerized version of the Wisconsin Card Sorting Test. J Autism Dev Disord, 38(6), 1161-1165. https://dx.doi.org/10.1007/s10803-007-0474-1

Karpinski, A. C., \& Scullin, M. H. (2009). Suggestibility under pressure: Theory of mind, executive function, and suggestibility in preschoolers. Journal of Applied Developmental Psychology, 30(6), 749-763. https://dx.doi.org/10.1016/j.appdev.2009.05.004

Korkmaz, B. (2011). Theory of mind and neurodevelopmental disorders of childhood. Pediatric Research, 69 , 101R-108R. https://dx.doi.org/10.1203/PDR.0b013e318212c177

Leslie, A. M., \& Frith, U. (1988). Autistic children's understanding of seeing, knowing and believing. British $\begin{array}{llll}\text { Journal of Developmental } & \text { 315-324. }\end{array}$ https://dx.doi.org/10.1111/j.2044-835X.1988.tb01104.x

MacLeod, C. M. (2007). The concept of inhibition in cognition. Inhibition in Cognition, 3-23. https://dx.doi.org/10.1037/11587-001

McLeod, S. A. (2007). Stages of Memory-Encoding Storage and Retrieval. Retrieved from http://www.simplypsychology.org/memory.html

Minshew, N. J., \& Goldstein, G. (2001). The pattern of intact and impaired memory functions in autism. Journal of Child Psychology and Psychiatry, 42(8), 1095-1101.

Minshew, N. J., Muenz, L. R., Goldstein, G., \& Payton, J. B. (1992). Neuropsychological functioning in non mentally retarded autistic individuals. Journal of Clinical and Experimental Neuropsychology, 14(5), 749-761. https://dx.doi.org/10.1080/01688639208402860

Mitchell, P. (1996). Acquiring a conception of mind; A review of psychological research and theory. Hove, East Sussex: Psychology Press.

Mottron, L., \& Belleville, S. (1993). A study of perceptual analysis in a high-level autistic subject with

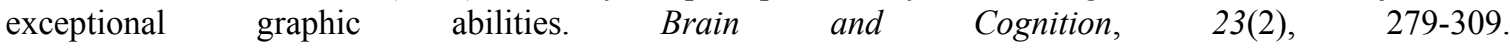
https://dx.doi.org/10.1006/brcg.1993.1060 
Nydén, A., Gillberg, C., Hjelmquist, E., \& Heiman, M. (1999). Executive function/attention deficits in boys with Asperger syndrome, attention disorder and reading/writing disorder. Autism, 3(3), 213-228. https://dx.doi.org/10.1177/1362361399003003002

O'Riordan, M. A., Plaisted, K. C., Driver, J., \& Baron-Cohen, S. (2001). Superior visual search in autism. Journal of Experimental Psychology; Human Perception and Performance, 27(3), 719. https://dx.doi.org/10.1037/0096-1523.27.3.719

Owen, A. M. (1997). Cognitive planning in humans; neuropsychological, neuroanatomical and neuropharmacological perspectives. Progress in Neurobiology, 53(4), 431-450. https://dx.doi.org/10.1016/S0301-0082(97)00042-7

Ozonoff, S., Cook, I., Coon, H., Dawson, G., Joseph, R. M., Klin, A., \& Pennington, B. F. (2004). Performance on Cambridge Neuropsychological Test Automated Battery subtests sensitive to frontal lobe function in people with autistic disorder; evidence from the Collaborative Programs of Excellence in Autism network. $J$ Autism Dev Disord, 34(2), 139-150. https://dx.doi.org/10.1023/B:JADD.0000022605.81989.cc

Ozonoff, S., \& Jensen, J. (1999). Brief report; Specific executive function profiles in three neurodevelopmental disorders. J Autism Dev Disord, 29(2), 171-177. https://dx.doi.org/10.1023/A:1023052913110

Ozonoff, S., \& McEvoy, R. E. (1994). A longitudinal study of executive function and theory of mind development in autism. Development and Psychopathology, 6(3), 415-431. https://dx.doi.org/10.1017/S0954579400006027

Ozonoff, S., Pennington, B. F., \& Rogers, S. J. (1991). Executive function deficits in high functioning autistic individuals; relationship to theory of mind. Journal of Child Psychology and Psychiatry, 32(7), 1081-1105. https://dx.doi.org/10.1111/j.1469-7610.1991.tb00351.x

Ozonoff, S., Rogers, S. J., \& Pennington, B. F. (1991). Asperger's Syndrome; Evidence of an Empirical Distinction from High-Functioning Autism. Journal of Child Psychology and Psychiatry, 32(7), 1107-1122. https://dx.doi.org/10.1111/j.1469-7610.1991.tb00352.x

Ozonoff, S., \& Strayer, D. L. (1997). Inhibitory function in nonretarded children with autism. J Autism Dev Disord, 27(1), 59-77. https://dx.doi.org/10.1023/A:1025821222046

Ozonoff, S., \& Strayer, D. L. (2001). Further evidence of intact working memory in autism. J Autism Dev Disord, 31(3), 257-263. https://dx.doi.org/10.1023/A:1010794902139

Ozonoff, S., Strayer, D. L., McMahon, W. M., \& Filloux, F. (1994). Executive function abilities in autism and Tourette syndrome; An information processing approach. Journal of Child Psychology and Psychiatry, 35(6), 1015-1032. https://dx.doi.org/10.1111/j.1469-7610.1994.tb01807.x

Pascualvaca, D. M., Fantie, B. D., Papageorgiou, M., \& Mirsky, A. F. (1998). Attentional capacities in children with autism; Is there a general deficit in shifting focus? J Autism Dev Disord, 28(6), 467-478. https://dx.doi.org/10.1023/A:1026091809650

Pellicano, E. (2010a). The Development of Core Cognitive Skills in Autism; A 3-Year Prospective Study. Child Development, 81(5), 1400-1416. https://dx.doi.org/10.1111/j.1467-8624.2010.01481.x

Pellicano, E. (2010b). Individual differences in executive function and central coherence predict developmental changes in theory of mind in autism. Developmental Psychology, 46(2), 530. https://dx.doi.org/10.1037/a0018287

Pellicano, E., Maybery, M., Durkin, K., \& Maley, A. (2006). Multiple cognitive capabilities/deficits in children with an autism spectrum disorder; "Weak" central coherence and its relationship to theory of mind and $\begin{array}{lllll}\text { executive control. Development and Psychopathology, 18(1), } & \text { 77-98. }\end{array}$ https://dx.doi.org/10.1017/S0954579406060056

Perner, J., Frith, U., Leslie, M. A., \& Leekam, R. S. (1989). Exploration of the Autistic Child's Theory of Mind; Knowledge, Belief, and Communication. Child Development, 60(3), 689-700. https://dx.doi.org/10.2307/1130734

Perner, J., \& Wimmer, H. (1985). "John thinks that Mary thinks that..." attribution of second order beliefs by 5to 10-year-old children. Journal of Experimental Child Psychology, 39(3), 437-471. https://dx.doi.org/10.1016/0022-0965(85)90051-7 
Plaisted, K., O'Riordan, M., \& Baron-Cohen, S. (1998). Enhanced visual search for a conjunctive target in autism; A research note. Journal of Child Psychology and Psychiatry, 39(5), 777-783. https://dx.doi.org/10.1017/S0021963098002613

Plaisted, K., Swettenham, J., \& Rees, L. (1999). Children with autism show local precedence in a divided attention task and global precedence in a selective attention task. Journal of Child Psychology and Psychiatry, 40(5), 733-742. https://dx.doi.org/10.1111/1469-7610.00489

Prior, M., \& Hoffmann, W. (1990). Brief report; Neuropsychological testing of autistic children through an exploration with frontal lobe tests. J Autism Dev Disord, 20(4), 581-590. https://dx.doi.org/10.1007/BF02216063

Rajendran, G., \& Mitchell, P. (2007). Cognitive theories of autism. Developmental Review, 27(2), 224-260. https://dx.doi.org/10.1016/j.dr.2007.02.001

Rinehart, N. J., Bradshaw, J. L., Moss, S. A., Brereton, A. V., \& Tonge, B. J. (2000). A typical interference of local detail on global processing in high-functioning autism and Asperger's disorder. Journal of Child Psychology and Psychiatry, 41(6), 769-778. https://dx.doi.org/10.1111/1469-7610.00664

Rinehart, N. J., Bradshaw, J. L., Moss, S. A., Brereton, A. V., \& Tonge, B. J. (2001). A deficit in shifting attention present in high-functioning autism but not Asperger's disorder. Autism, 5(1), 67-80. https://dx.doi.org/10.1177/1362361301005001007

Robinson, S., Goddard, L., Dritschel, B., Wisley, M., \& Howlin, P. (2009). Executive functions in children with autism spectrum disorders. Brain and Cognition, 71(3), 362-368. https://dx.doi.org/10.1016/j.bandc.2009.06.007

Ropar, D., \& Mitchell, P. (1999). Are individuals with autism and Asperger's syndrome susceptible to visual illusions? Journal of Child Psychology and Psychiatry, 40(8), 1283-1293. https://dx.doi.org/10.1111/1469-7610.00544

Ropar, D., \& Mitchell, P. (2001). Susceptibility to illusions and performance on visuospatial tasks in individuals with autism. Journal of Child Psychology and Psychiatry, 42(4), 539-549. https://dx.doi.org/10.1111/1469-7610.00748

Rumsey, J. M., \& Hamburger, S. D. (1988). Neuropsychological findings in high-functioning men with infantile autism, residual state. Journal of Clinical and Experimental Neuropsychology, 10(2), 201-221. https://dx.doi.org/10.1080/01688638808408236

Rumsey, J. M., \& Hamburger, S. D. (1990). Neuropsychological divergence of high-level autism and severe dyslexia. J Autism Dev Disord, 20(2), 155-168. https://dx.doi.org/10.1007/BF02284715

Russell, J., Hala, S., \& Hill, E. (2003). The automated windows task; the performance of preschool children, children with autism, and children with moderate learning difficulties. Cognitive Development, 18(1), 111-137. https://dx.doi.org/10.1016/S0885-2014(02)00163-6

Russell, J., Jarrold, C., \& Hood, B. (1999). Two intact executive capacities in children with autism; Implications for the core executive dysfunctions in the disorder. J Autism Dev Disord, 29(2), 103-112. https://dx.doi.org/10.1023/A:1023084425406

Russell, J., Mauthner, N., Sharpe, S., \& Tidswell, T. (1991). The "windows task" as a measure of strategic deception in preschoolers and autistic subjects. British Journal of Developmental Psychology, 9(2), 331-349. https://dx.doi.org/10.1111/j.2044-835X.1991.tb00881.x

Scott, W. A. (1962). Cognitive complexity and cognitive flexibility. Sociometry, 405-414. https://dx.doi.org/10.2307/2785779

Shah, A., \& Frith, U. (1983). An islet of ability in autistic children; A research note. Journal of Child Psychology and Psychiatry, 24(4), 613-620. https://dx.doi.org/10.1111/j.1469-7610.1983.tb00137.x

Shah, A., \& Frith, U. (1993). Why do autistic individuals show superior performance on the block design task? Journal of Child Psychology and Psychiatry, 34(8), 1351-1364. https://dx.doi.org/10.1111/j.1469-7610.1993.tb02095.x

Shu, B. C., Tien, A. Y., \& Chen, B. C. (2001). Executive function deficits in non-retarded autistic children. Autism, 5(2), 165-174. https://dx.doi.org/10.1177/1362361301005002006 
Silverstein, A. (1970). Reappraisal of the validity of WAIS, WISC, and WPPSI short forms. Journal of Consulting and Clinical Psychology, 34(1), 12. https://dx.doi.org/10.1037/h0028680

Squire, L. R., \& Dede, A. J. (2015). Conscious and Unconscious Memory Systems. Cold Spring Harbor Perspectives in Biology, 7(3), a021667. https://dx.doi.org/10.1101/cshperspect.a021667

Steele, S. D., Minshew, N. J., Luna, B., \& Sweeney, J. A. (2007). Spatial working memory deficits in autism. $J$ Autism Dev Disord, 37(4), 605-612. https://dx.doi.org/10.1007/s10803-006-0202-2

Tager-Flusberg, H. (1999). A psychological approach to understanding the social and language impairments in autism. International Review of Psychiatry, 11(4), 325-334. https://dx.doi.org/10.1080/09540269974203

Van Eylen, L., Boets, B., Steyaert, J., Evers, K., Wagemans, J., \& Noens, I. (2011). Cognitive flexibility in autism spectrum disorder; Explaining the inconsistencies? Research in Autism Spectrum Disorders, 5(4), 1390-1401. https://dx.doi.org/10.1016/j.rasd.2011.01.025

van Nieuwenhuijzen, M., \& Vriens, A. (2012). (Social) Cognitive skills and social information processing in children with mild to borderline intellectual disabilities. Research in Developmental Disabilities, 33(2), 426-434. https://dx.doi.org/10.1016/j.ridd.2011.09.025

Verte, S., Geurts, H. M., Roeyers, H., Oosterlaan, J., \& Sergeant, J. A. (2006). Executive functioning in children with an autism spectrum disorder; Can we differentiate within the spectrum? J Autism Dev Disord, 36(3), 351-372. https://dx.doi.org/10.1007/s10803-006-0074-5

Williams, D. L., Goldstein, G., Carpenter, P. A., \& Minshew, N. J. (2005). Verbal and spatial working memory in autism. J Autism Dev Disord, 35(6), 747-756. https://dx.doi.org/10.1007/s10803-005-0021-x

Wimmer, H., \& Perner, J. (1983). Beliefs about beliefs; Representation and constraining function of wrong beliefs in young children's understanding of deception. Cognition, 13(1), 103-128. https://dx.doi.org/10.1016/0010-0277(83)90004-5

Yerys, B. E., Wallace, G. L., Harrison, B., Celano, M. J., Giedd, J. N., \& Kenworthy, L. E. (2009). Set-shifting in children with autism spectrum disorders; Reversal shifting deficits on the Intradimensional /Extradimensional Shift Test correlate with repetitive behaviors. Autism: The International Journal of Research and Practice, 13(5), 523-538. https://dx.doi.org/10.1177/1362361309335716

Zaitchik, D. (1990). When representations conflict with reality; The preschooler's problem with false beliefs and "false" photographs. Cognition, 35(1), 41-68. https://dx.doi.org/10.1016/0010-0277(90)90036-J

Zinke, K., Fries, E., Altgassen, M., Kirschbaum, C., Dettenborn, L., \& Kliegel, M. (2010). Visuospatial short-term memory explains deficits in tower task planning in high functioning children with autism spectrum disorder. Child Neuropsychology, 16(3), 229-241. https://dx.doi.org/10.1080/09297040903559648

\section{Appendix A}

\section{1) First-order false belief tests}

Unexpected transfer scenario (Wimmer \& Perner, 1983; Simon Baron-Cohen et al., 1985).

The children saw a character, Maria, placing a marble in a handbag and then leaving the scene. While Maria was absent, another character, Kostas, transferred the marble in a box. Initially, children were asked by the experimenter the false belief question: "Where will Maria look for her marble?". Children were also asked a control question: "Where is the marble really?", and a memory question: "Where was the marble at the beginning?".

Unexpected replacement task (Pellicano et al., 2006)

The children saw a character, Helen, placing a ring in a box and then leaving the scene. Another character, John, while Helen was not present, removed the ring and replaced it with a pencil sharpener. Initially, the children were asked the false belief question: "What does Helen think is inside the box?". They were also asked a control question: "What is really inside the box?", and a memory question: "What had been placed inside the box at the beginning?". 


\section{Unexpected content task (Perner et al., 1989)}

The children were shown a closed Smarties box whose content had been replaced with pencils and they were asked what they thought was inside. Then the experimenter revealed the true content and children were then asked a memory question requiring them to recall their own false belief: "Before you looked inside, what did you think was in the box?", and a reality control question: "What is really in the box?". Afterwards, a teddy bear was taken out and placed in front of the box. The children were asked the false belief test question to predict the teddy bear's false belief, "What will the teddy bear think is inside the box?".

\section{2) Second-order false belief tests}

Trial of unexpected transfer of object (Pellicano et al., 2006).

The children saw a character, Helen, placing a miniature teddy bear in a handbag and then leave the scene. While Helen was not there, another character, John, moved the teddy bear to a different place, inside a box. However, unbeknownst to John, Helen was watching the transfer through a window. Initially, the children were asked by the experimenter the false belief question: "Where will John think that Helen will search for her object?". The children were also asked a control question: "Where is teddy bear really?", and a memory question: "Where did Helen place the teddy bear at the beginning?".

\section{Two modified scenarios from Perner and Wimmer's (1985) stories}

\section{$1^{\text {st }}$ scenario}

The children saw three characters: Kostas, John and Stavros, who agreed to meet in the afternoon at school to play football. However, Kostas called John and told him that instead of meeting at school, it would be better to meet at the playground. Stavros was not informed about this change and John took on the responsibility of going to Stavros' house in the afternoon to pick him up and take him to the playground instead of school.

In the afternoon, as Kostas was going towards the playground, he passed Stavros' house. Stavros spotted him from his balcony and asked him where he was going. Kostas informed him that the meeting point had changed and he was going towards the playground. Stavros told him to wait for a second and they went to the playground together. But John didn't know that Kostas had met Stavros and had gone to the playground together. John went to pick Stavros up from his house, rang the bell and Stavros' father opened the door. John asked him where Stavros was and the father replied that Stavros had gone to play football.

Initially, the children were asked by the experimenter the false belief question: "Where will John think Stavros has gone?". The children were also asked a control question: "Where in fact are Kostas and Stavros?", and a memory question: "Where was the meeting point at the beginning?".

\section{$2^{\text {nd }}$ scenario}

The children saw two characters, John and Mary, together in the park. In the park there was also an ice-cream man, Mr. Nikos, in his van. Mary wanted to buy an ice cream but she had left her money at home. So she decided to go home to get some money and return to the park to buy some ice cream. She told John to wait for her. While Mary was away, John saw Mr. Nikos leaving the park. John asked Mr. Nikos where he was going and Mr. Nikos replied that he was driving his van behind the church to sell ice cream. While Mr. Nikos was driving his van over to the church, he passed Mary's house. Mary saw him from her balcony and asked him where he was going. He replied that he was going behind the church to sell ice cream. Then, Mary left her house and went right away behind the church to buy some ice cream. But John didn't know that Mary had talked to the ice-cream man. He went over to Mary's house, rang the bell and Mary's father opened the door. John asked where Mary was and her father replied that she had gone to buy some ice cream.

Initially, the children were asked by the experimenter the false belief question: "Where will John think that Mary has gone?". The children were also asked a control question: "Does John know that the ice-cream man has talked to Mary?", and a memory question: "Where was the ice-cream man at the beginning?".

\section{3) Trials Faux Pas test}

\section{Two modified Faux Pas test scenarios (Baron-Cohen et al., 1999).}

\section{$1^{\text {st }}$ scenario}

The children saw three characters: Uncle Sakis, Helen and Helen's mother. Helen and her mother made an apple-pie for Uncle Sakis, who was going to visit them. When he entered the house, Helen announced that she had made a pie for him. Uncle Sakis replied: "Thanks Helen, I hope it's not an apple pie, I hate apples". 
Initially, the children were asked by the experimenter the Faux Pas question: "In the story did someone say something that they should not have said?" The children were also asked an identification question: "What did they say that they should not have said?", a control question: "What kind of pie did Helen make for her uncle?", and a false belief question: "Did Uncle Sakis know the pie was an apple pie?".

\section{$2^{\text {nd }}$ scenario}

The children saw three characters: Kostas, John and Peter. Peter was inside the school WC. A few seconds later, Kostas and John went to the toilet to wash their hands. Kostas said to John: "Do you know Peter, the new boy that has just arrived in our school. I don't like him at all, he's weird". At that moment, Peter stepped out of the WC and John said to him: "Hi Peter, would you like to play football with me?".

Initially, the children were asked by the experimenter the Faux Pas question: "In the story did someone say something that they should not have said?". The children were also asked an identification question: "What did they say that they should not have said?, a control question: "Where were Kostas and John while they were talking to each other?", and a false belief question: "Did Kostas know that Peter was inside the toilet?".

\section{Copyrights}

Copyright for this article is retained by the author(s), with first publication rights granted to the journal.

This is an open-access article distributed under the terms and conditions of the Creative Commons Attribution license (http://creativecommons.org/licenses/by/4.0/). 